\title{
Entre ejecutivos republicanos y regencias dinásticas. Desafíos y dile- mas en el escenario de las Cortes de Cádiz, 1810-1814*
}

\author{
Marcela Ternavasio ${ }^{1}$ \\ Universidad de Rosario, Argentina \\ marcelaternavasio@gmail.com
}

RESUMEN: El objetivo del artículo es explorar los desafios y dilemas que expresaron las propuestas dinásticas que pujaron por ocupar el trono vacante de España durante los años en los que sesionaron las Cortes Generales y Extraordinarias y el breve periodo de las Cortes Ordinarias (1810-1814). El análisis se concentra en las redes de vínculos políticos trabados alrededor de las candidaturas dinásticas a través de una nutrida correspondencia pública y privada, de algunos impresos que circularon y de los debates desplegados en las Cortes. Este estudio presenta, por un lado, el trabajo de adaptación que, en el registro de las prácticas políticas, realizaron los operadores de dichas candidaturas en un escenario atravesado por el impacto de la soberanía popular y de la guerra de opinión que signó a la experiencia gaditana; por otro lado, reubica los interrogantes que se instalaron en torno al carácter perpetuo e interino del gobierno poniendo en juego los tiempos de esa monarquía hereditaria. Las variaciones que exhiben las estrategias, alianzas y argumentos desplegados en ese contexto permiten situar el centro de esta reflexión: las dificultades nacidas del intento por compatibilizar el tradicional principio de linaje dinástico con el enigma que presentaba la nueva naturaleza del poder ejecutivo moderno.

\section{PALABRAS CLAVE: linaje; dinastía; división de poderes; soberanía po- pular; poder ejecutivo; redes políticas.}

* Archivos citados: Arqhivo Histórico Museo Imperial, Petrópolis (AHMI); Arquivo Nacional da Torre do Tombo, Lisboa (ANTT); Archivo Histórico Nacional, Madrid (AHN); Archivo del Ministerio de Relaciones Exteriores, Itamaraty (AMRE); Biblioteca Nacional, Madrid (BN); Biblioteca del Senado de España, Madrid (BSE); Foreign Office Archives, Londres (FOA) y Mayo Documental, Universidad de Buenos Aires, Facultad de Filosofía y Letras, 1962 (MD).

${ }^{1}$ ORCID iD: https://orcid.org/0000-0003-3297-6449.

Copyright: (C) 2018 CSIC. Este es un artículo de acceso abierto distribuido bajo los términos de una licencia de uso y distribución Creative Commons Reconocimiento 4.0 Internacional (CC-BY 4.0) 


\title{
Between republican executives and dynastic regencies. Challenges and dilemmas in
} the Cádiz Cortes, 1810-1814

\begin{abstract}
The aim of this article is to explore the challenges and dilemmas expressed by the dynastic proposals that sought to occupy the vacant throne of Spain during the years of the General and Extraordinary Cortes, and the brief period of the Ordinary Cortes (1810-1814). The analysis focuses on the networks of political ties drawn around the dynastic candidacies by exploring a large corpus of correspondence - both public and private- as well as printed pamphlets and the debates of the Cortes. I propose, on the one hand, to show how the recording of political practices was adapted by the operators of these candidacies, in a scenario affected by the impact of popular sovereignty and the war of opinion that marked the experience of the Cortes. On the other hand, I aim to review questions that arose regarding the perpetual or interim character of the government jeopardizing the timing of the hereditary monarchy. The variations exhibited by the strategies, alliances and arguments deployed in this context bring us to the crux of the issue: the difficulties arising from the attempt to reconcile the traditional principle of dynastic lineage with the enigma presented by the new nature of modern executive power.
\end{abstract}

KEY WORDS: lineage; dynasty; division of powers; popular sovereignty; executive branch; political networks.

CÓMO CITAR ESTE ARTÍCULO/CITATION: Ternavasio, Marcela, «Entre ejecutivos republicanos y regencias dinásticas. Desafíos y dilemas en el escenario de las Cortes de Cádiz, 1810-1814», Hispania, 78/260 (Madrid, 2018): 701-730. https://doi.org/10.3989/hispania.2018.016

La crisis de la monarquía española que derivó en la convocatoria a Cortes y en la sanción de la Constitución de 1812 es tal vez uno de los temas más tratados en los últimos años por parte de la historiografía especializada a ambos lados del Atlántico. A estas alturas pareciera que es muy poco lo que se puede agregar a tan abundante y calificada producción. No obstante, en este artículo me propongo regresar sobre «el momento gaditano» — según la denominación acuñada en el estudio dirigido por Marta Lorente y José María Portillo Valdés - , para explorar los desafíos y dilemas que expresaron las propuestas dinásticas que pujaron por ocupar el trono vacante a partir de que las Cortes reunidas en la Isla de León asumieron la potestad soberana y establecieron la distinción tripartita de poderes².

2 LORENTE Y PORTILLO VALDÉS, 2012. Sería imposible hacer justicia con toda la producción historiográfica existente sobre el «momento gaditano». Por ello vale aclarar, de entrada, que la bibliografía citada a continuación es sólo una ínfima parte de la que me ha inspirado en estas páginas. 
Como sabemos, la situación extraordinaria por la que atravesaba la monarquía española reactualizó el debate en torno a la tradicional figura de la Regencia y a la controvertida ley de Sucesión. La primera, destinada a cubrir los interregnos de minoridad o incapacidad de un rey, difícilmente podía acomodarse a la vacancia creada en 1808; y la segunda se hallaba «en suspenso» luego de la sinuosa trayectoria que experimentó desde que Felipe V fijara la ley Sálica en 1713. Una vez reunida la Asamblea gaditana, dominada por los grupos liberales y reformistas, ambas cuestiones emergieron muy entrelazadas. El primer Consejo de Regencia que sustituyó a la Junta Suprema a fines de enero de 1810 fue habilitado como poder ejecutivo interino y, de allí en adelante, las sucesivas regencias se convirtieron en una suerte de «ejecutivos republicanos» y colegiados elegidos por las Cortes, limitados en el tiempo y en sus atribuciones, y sometidos férreamente al poder constituyente y legislativo $^{3}$. Estos débiles ejecutivos estuvieron en constante conflicto con la Asamblea hasta que Fernando VII puso fin a la experiencia constituyente con el decreto del 4 de mayo de 18144. En el marco de esos conflictos, y en oposición a los ejecutivos republicanos, se colaron siempre las presiones que ejercieron los grupos que postularon para colocar como cabeza de la Regencia a un miembro del linaje borbónico mientras se debatía la futura ley de Sucesión sancionada finalmente en la Constitución de 1812.

Las disputas suscitadas alrededor del debate por la ley de Sucesión y de quiénes debían ocupar interinamente el nuevo poder ejecutivo, ponen de relieve al menos dos cuestiones que requieren ser distinguidas. Una, de carácter jurídico, se refiere a las dificultades por conciliar el viejo orden legal de la monarquía con el nuevo orden legal que intentaba montarse sobre el nuevo dispositivo constitucional de división de poderes; la otra, remite a las correlaciones de fuerzas y prácticas políticas que se desplegaron tanto en las Cortes como en el seno de una opinión pública muy movilizada. Este artículo se concentra en la segunda cuestión pero intenta iluminar algunos problemas que atañen a la primera.

A partir del análisis de las redes de vínculos políticos trabados alrededor de las candidaturas dinásticas - explorados a través de una nutrida correspondencia pública y privada, de algunos impresos que circularon y de los debates desplegados en las Cortes-, me propongo presentar el «trabajo» de adaptación que, en el registro de las prácticas políticas, realizaron los operadores de dichas candidaturas, y reubicar los interrogantes que se instalaron en torno al carácter «perpetuo» e «interino» del gobierno que pusieron en juego los «tiempos» de esa monarquía hereditaria. Las variaciones que exhiben las estrategias, alianzas y argumentos desplegados en ese contexto, atravesado por el impacto de la so-

3 LORENTE Y PORTILLO VALDÉS, 2012: 244.

4 FLAQUER MONTEQUI, 2003. 
beranía popular y la guerra de opinión que signó a la experiencia gaditana, permiten situar el centro de esta reflexión: las dificultades nacidas del intento por compatibilizar el tradicional principio de linaje dinástico con el enigma que presentaba la nueva naturaleza del poder ejecutivo moderno.

\section{EL CENTRO DEL PROBLEMA}

En un impreso anónimo, titulado Discurso sobre el peligro de la Patria editado en Cádiz en 1811, el autor se hacía eco de los debates suscitados en las Cortes en ocasión de una de las sucesivas crisis que afectó a la Regencia:

Constituir de otro modo el gobierno: que sin separar a los actuales señores regentes, se aumenten otros dos, y se elija a la princesa Carlota para presidir la Regencia [...].

Los más desean un gobierno mejor constituido que el actual, y que con actividad y energía (que no consisten en tener facultades por la ley, si no acompañan las disposiciones física y moral de los agentes) ponga en movimiento todos los recursos que aún tiene la nación [...].

Añadir otros dos regentes a los que hay. ¿Para qué? ¡Cuando es necesario un dictador, debilitar la acción del gobierno aumentando muelles y más muelles a la máquina, unos nuevos y otros usados! Si parecen buenos los señores regentes actuales al Sr. diputado autor de las proposiciones, no debía aumentar más que a la princesa Carlota, que es lo que faltaba para el objeto de que esté al frente una persona real ${ }^{5}$.

En el impreso se presentaban las dos alternativas en danza - la que regía de una Regencia colegiada elegida por las Cortes entre «personas particulares» y la que postulaba designar una «persona real», ya sea para asumirla de manera unipersonal o para presidirla-, y una tercera opción que recuperaba la tradición republicana clásica: «quisiera que pudiéramos hacer lo que los romanos, cuando la república estaba en peligro, pero no se ha dado a conocer el que pudiera ser nuestro dictador ni por un año, ni por seis meses, ni por un día» ${ }^{6}$.

El interrogante central del publicista era el que circulaba desde que se produjo la crisis de 1808: ¿cómo garantizar, en aquel escenario político, la obediencia de esa inmensa monarquía acostumbrada a aceptar la autoridad real fundada en el principio de linaje? Dicho principio se había instituido desde el Medioevo en la garantía de perpetuidad de una dinastía y en el reaseguro para que el carácter político y corporativo de la Corona no sufriera los peligrosos interregnos que implicaba la muerte de un monarca. La Guerra de

5 Discurso sobre el peligro de la Patria, Cádiz, Imprenta Vicente Lema, 1811, BSE, 38158 (III): 3. Agradezco a Ivana Frasquet haberme enviado el documento completo.

6 Discurso sobre el peligro de la Patria, Cádiz, Imprenta Vicente Lema, 1811, BSE, 38158 (III): 5. 
Sucesión por la muerte sin descendencia del último Habsburgo lo había puesto a prueba, pero el de 1808 era, sin duda, un interregno mucho más peligroso: el rey no estaba muerto sino que había renunciado ilegalmente a la Corona para entregarla a un rey «extranjero», mientras diversos cuerpos y partidos disputaban jurídica y políticamente para reemplazarlo en su particular ausencia. La eficaz imagen construida en torno al «Rey Deseado» pudo funcionar como aglutinante en los primeros tramos de la crisis para que las juntas ocuparan el vacío en calidad de depósito del poder soberano y para hacer fracasar las propuestas de Regencia lideradas por los sectores más conservadores como las candidaturas dinásticas que circularon. Esa imagen, sin embargo, se fue tornando insuficiente para dotar de unidad a un gobierno que, una vez reunidas las Cortes, procuraba infructuosamente asegurar la obediencia política de todo el imperio ${ }^{7}$.

Ya ha sido destacado que el término "gobierno» experimentó en esa coyuntura una redefinición semántica que habilitó a diversos usos y significados ${ }^{8}$. Frente a la pregunta sobre quiénes estaban llamados a gobernar, y luego de las conocidas respuestas que se sucedieron y ensayaron entre los sucesos de Bayona y la reunión de las Cortes, la división de las tres potestades establecida por la Asamblea gaditana (de hacer las leyes, de ejecutarlas y de aplicarlas) no resolvió el problema sino que lo amplificó al insertarse en lo que se ha dado en llamar «constitucionalismo jurisdiccional»" ${ }^{9}$ En el marco de la guerra contra Francia y de la fragmentación que desató la crisis (de gobiernos centrales, provinciales y locales), la «unidad del gobierno» aparecía como una necesidad pero también como una incógnita. El reclamo de unidad no lograba anclar ni en la tradición histórica ni en el nuevo lenguaje constitucional.

La tradición histórica indicaba que en la monarquía hispánica, entre los siglos XVI y XVIII, el rey no gobernaba (reinar significaba hacer justicia), ni monopolizaba la gestión de la jurisdicción (sólo era la fuente de ésta y por ello gozaba de una posición preeminente $)^{10}$, ni los fundamentos de su autoridad derivaban de manera directa del origen divino (como ocurría en otras monarquías) aunque la obligación política se comprendiera y expresara en términos religiosos ${ }^{11}$. A su vez, en el idioma constitucional moderno el poder ejecutivo encerraba un misterio que era precisamente el de su «unidad». Puesto que el cuerpo legislativo, a pesar de su potencia como poder supremo, no podía encarnar la unidad política de los miembros y cuerpos de la sociedad por su misma naturaleza representativa de opiniones e intereses diversos, la

\footnotetext{
7 PORTILLO VALDÉS, 2000; 2006.

8 GARRIGA, 2008.

9 GARRIGA y LORENTE, 2007.

10 CLAVERO, 1996: 15-16.

11 LANDAVAZO, 2001: 67-68.
} 
nueva ficción legitimadora de la soberanía de la nación que proclamaron las Cortes era insuficiente para alcanzar la «unidad de la acción», propia del poder ejecutivo moderno ${ }^{12}$.

Sobre la naturaleza del poder ejecutivo, la historiografía constitucional ha dedicado ríos de tinta. No es mi propósito detenerme en las diversas perspectivas postuladas dentro de este amplio campo sino sólo retomar la clave interpretativa que, desde la historia crítica del derecho, postuló Bartolomé Clavero en su esclarecedor estudio sobre «El orden de los poderes». El autor propone allí despegarse de los tradicionales análisis que exploran el problema desde la historia de las ideas para instalarse en el de las disputas políticas y constitucionales concretas que dieron lugar a la creación del dispositivo de división de poderes, cuya radical modernidad y originalidad destaca. Demostrar el carácter histórico de la «fórmula trinitaria» implica, para Clavero, desnaturalizar la idea de que la misma remite a «unas teorías puras» para desplazarse a la de las «plasmaciones prácticas» que, desde sus inicios, dejaron planteadas «cuestiones inseguras y problemáticas» en las diversas latitudes en las que se fueron sucediendo los diversos ensayos constituyentes ${ }^{13}$. Y tal vez una de las cuestiones más inseguras y problemáticas que debieron enfrentar los hacedores de constituciones fue definir el lugar y las atribuciones del poder ejecutivo.

Este desafío, común para las monarquías constitucionales y las nuevas repúblicas, se presentó más problemático para los constituyentes gaditanos. Por un lado, las Cortes de Cádiz tuvieron que abocarse a definir el nuevo estatus constitucional y los límites al poder del monarca para acomodarlo al principio tripartito de poderes, como cabeza del ejecutivo sometido a control aunque sin responsabilidad ${ }^{14}$. Desde hacía dos siglos circulaba en el orbe occidental la potente idea de que el poder gestionado por los gobiernos - cualquiera fuera el referente al que aludiera la polisémica voz «gobierno»-, debía ser limitado; una idea que estuvo muy presente en el debate español desde el setecientos y que marcó el de las Cortes gaditanas ${ }^{15}$. Por otro lado, mientras limitar el poder del monarca en un contexto de monarquía constitucional con un rey ausente era una apuesta hacia un futuro incierto, el presente obligaba a las Cortes a resolver dos cuestiones: la problemática ley de Sucesión dinástica y el debate sobre quiénes - y con qué atribuciones-, ocuparían provisoriamente el poder ejecutivo ejercido por las sucesivas regencias durante el cautiverio de Fernando VII. Ambas cuestiones exigían bucear en las propias tradiciones y viejas «leyes fundamentales».

12 MANENT, 1990: 123-124.

13 CLAVERO, 2007: 26 y 39.

14 LASARTE, 2009. MARTÍNEZ SOSPREDA, 2012. VARELA SUANZES-CARPEGNA, 1987.

15 LORENTE Y PORTILLO VALDÉS, 2012: 239.

Hispania, 2018, vol. LXXVIII, nº. 260, septiembre-diciembre, págs. 701-730, ISSN: 0018-2141, e-ISSN: 1988-8368 https://oi.org/10.3989/hispania.2018.016 
Así ocurrió con la indagación del derrotero de la ley de Sucesión, conceptuada como ley fundamental y entre las pocas que no eran susceptibles de modulación por la tradición. La ley Sálica impuesta por el primer Borbón en 1713 fue anulada por las Cortes reunidas en 1789 para regresar a las normas establecidas por el código de las Partidas. La resolución, sin embargo, no fue formalizada por medio de una ley, cédula o pragmática. El Rey Carlos IV había dado órdenes a los procuradores de que dicha resolución mantuviera carácter secreto una vez que se disolviesen las Cortes para no despertar apetencias por parte de las potenciales ramas herederas al trono. En 1808 era oficialmente desconocida. En la peculiar situación de aquella coyuntura, con la familia real cautiva en Francia, el tema regresa en toda su potencia: no era un detalle menor discutir si las mujeres podían reinar en ausencia de hermanos varones y con preferencia sobre los varones de parentesco más lejano.

Con el debate acerca del gobierno provisorio, la indagación histórica resultaba más complicada si se intentaba fundamentar una Regencia de «persona real» en las antiguas leyes fundamentales. El Consejo de Castilla ya lo había intentado sin éxito en la Consulta de octubre de 1808 al reclamar la «observancia de las Leyes Fundamentales» avalada por la ley de Partida 3, 3, 15; pero ni la situación de minoridad ni la de incapacidad del rey que preveía dicha ley se ajustaba a lo ocurrido en 1808. Los mismos consejeros podían reconocerlo al apelar en dicha oportunidad a una lógica argumentativa de carácter analógico: aunque intentaron inferir que dicha ley «es aplicable a la impotencia proveniente del cautiverio o prisión», debieron a la vez reconocer que los sucesos de esos días no ofrecían «en la historia otro semejante» capaz de despertar «la perspicacia del más sabio legislador» ${ }^{16}$. Así, pues, si la figura de la Regencia había sido siempre percibida como un interregno inseguro durante la minoridad o incapacidad de un monarca, la nueva Regencia creada en Cádiz estaba condenada a ser aún más débil porque venía a ocupar el «hueco» dejado por su renuncia — según la expresión de Martínez Sospre$\mathrm{da}-$, sin contar con su legitimidad ni su permanencia ${ }^{17}$.

El reclamo que circulaba entonces, y del que se hacía vocero el publicista citado al comienzo, de no «debilitar la 'acción del gobierno'» no podía si no asociarse al desafío de cómo recomponer y garantizar la obediencia política de todo el imperio. La cuestión de la obligación política estaba en la base de la condición insegura e inestable en la que se encontraba todo intento de compatibilizar los fundamentos sobre los cuales se había asentado la figura del monarca desde tiempo inmemorial con el nuevo idioma constitucional. En este sentido, como han indicado Garriga y Lorente, puesto que el proceso constituyente doceañista adquirió un tono marcadamente historicista al invo-

16 AHN, Estado, 3566, exp. 57: 170-172.

17 MARTÍNEZ SOSPREDA, 2012: 74. 
car las «viejas leyes fundamentales», «impuso una manera de articular las relaciones entre derecho viejo y derecho nuevo que subordinó la actividad legislativa a la compatibilidad entre la Constitución y las antiguas leyes de la monarquía católica» ${ }^{18}$. Un solapamiento que queda claramente exhibido en las disputas que se analizan en las siguientes páginas.

Si regresamos a los dichos del impreso anónimo podemos inferir que la apelación al dictador de la tradición romana, habitual en aquellos conflictivos años, era un argumento eficaz para poner en evidencia el problema. El diagnóstico se reducía, para su autor, a tener como «muy conveniente que haya al frente una persona real, porque se le obedecerá mejor que a los regentes, siendo personas particulares, y que se respetarán mejor las órdenes, especialmente en los ejércitos» ${ }^{19}$. Era éste un lugar común entre los grupos realistas que se oponían al partido liberal que pretendía mantener ejecutivos débiles designados por las Cortes. No obstante, el impreso no dejaba de interrogarse sobre ese lugar común:

\begin{abstract}
¿Qué haríamos con el regente persona real? A los regentes particulares les puede remover la nación sin más causa, que el no ser útiles o no serlo tanto como se necesite [...]. Y qué, ¿tendríamos la misma facilidad con una persona real de la casa reinante, y menos si fuese la presunta sucesora al trono? ¿No habría división de opiniones, y aún de partidos siempre temibles? ${ }^{20}$
\end{abstract}

Poner en duda la eficacia del principio dinástico sobre el que se había organizado la continuidad de - y la obediencia a - esa monarquía compuesta - «ipues por qué la Regencia de España ha de necesitar de una persona real para que se la respete y obedezca?» ${ }^{21}$, y desarmar el argumento de que la supuesta deferencia hacia el linaje de la realeza evitaría la división de partidos exhibía muy bien el escenario en el que se estaba debatiendo el problema.

\title{
LOS IMPRESOS «REALES»
}

¿Quiénes fueron los candidatos más firmes a disputar simultáneamente la ley de Sucesión y la Regencia interina en esta etapa? Básicamente los que provenían de la rama borbónica del Rey de Nápoles y las dos Sicilias y de la

18 GARRIGA y LORENTE, 2007: 37-38.

19 Discurso sobre el peligro de la Patria, Cádiz, Imprenta Vicente Lema, 1811, BSE, 38158 (III): 6.

20 Discurso sobre el peligro de la Patria, Cádiz, Imprenta Vicente Lema, 1811, BSE, 38158 (III): 8.

21 Discurso sobre el peligro de la Patria, Cádiz, Imprenta Vicente Lema, 1811, BSE, 38158 (III): 7. 
rama emparentada con los Braganza ${ }^{22}$. En este último caso se encontraban los dos infantes que competían entre sí, dentro de la misma Corte a la que pertenecían, y que se hallaban en Río de Janeiro luego del mítico viaje transatlántico que emprendió toda la familia real portuguesa en noviembre de 1807 frente a la invasión de las tropas napoleónicas en la Península: Carlota Joaquina de Borbón - hermana mayor de Fernando VII y esposa del príncipe regente de Portugal y futuro João VI- , y el infante Pedro Carlos de Borbón y Braganza - hijo del hermano de Carlos IV, Gabriel de Borbón, y de la infanta Mariana Victoria de Portugal-, quien al quedar huérfano de pequeño fue enviado a la Corte de Braganza para criarse con su familia materna. Ambos habían reclamado en agosto de 1808 sus derechos a ocupar la Regencia en América frente a la acefalía de la Corona a través de los célebres manifiestos que circularon en toda América y España ${ }^{23}$. Por diversas razones, vinculadas a la política interna portuguesa como a las redes desplegadas en el ámbito peninsular, la candidatura que se mantuvo en pie fue la de la infanta Carlota ${ }^{24}$. Al tomar estado público lo acontecido en las Cortes de 1789, se reforzaba el plan portugués de ver reconocidos los derechos sucesorios a la Corona de la hija mayor de Carlos IV 25 . No obstante, este plan complicaba el debate por los reclamos a la Regencia al quedar ambas cuestiones vinculadas en el debate político de coyuntura ${ }^{26}$.

En ese contexto, las disputas entre las candidaturas dinásticas se expresaron a través de diversos tipos de papeles públicos: manifiestos y memorias de los respectivos ministros plenipotenciarios dirigidos a las Cortes, artículos en la prensa periódica, impresos de diversos autores y también anónimos. Respecto de los primeros, se destaca la extensa memoria que el embajador portugués en Cádiz, Pedro de Sousa Holstein, preparó para ser distribuida previamente entre los diputados y remitida a las Cortes en noviembre de 1810. En ella, el ministro hacía un detallado historial de todo lo ocurrido con la ley de Sucesión durante el siglo XVIII e informaba de sus gestiones precedentes y del reconocimiento que había obtenido por parte del Consejo Reunido y luego

22 Además se hallaba la rama borbónica francesa con Luis Felipe, duque de Orleans, a la cabeza. Pero las pretensiones de la rama francesa no obtuvieron apoyos para instalarse como alternativa.

23 Justa Reclamación; Manifiesto dirigido a los Fieles Vasallos; Respuesta de S.A.R. el Príncipe Regente de Portugal; Don Pedro Carlos de Borbón y Braganza al Príncipe Regente de Portugal, Río de Janeiro, 19-20/08/1808, BN, leg. 1155, 19511.

24 RUBIO, 1920. TERNAVASIO, 2015.

${ }_{25}$ Manifiesto Junta de Murcia, junio de 1808, Informe, Río de Janeiro, 24/02/1809, MD, t. 8: 41 .

26 BRANCATO, 2003. COSTA, 2013. LA PARRA, 2017. MARTIRÉ, 2009. NOGUEIRA DE AZEVEDO, 2002. MARQUES PEREIRA, 1999. TERNAVASIO, 2015. 
del primer Consejo de Regencia sobre los derechos sucesorios de Carlota ${ }^{27}$. En tal dirección instaba a las Cortes a formalizar ese reconocimiento y admitir lo decidido en las Cortes de 178928. A su vez, el encargado de negocios extranjeros de Nápoles y las Dos Sicilias, Gerardo Robertone, al tomar conocimiento del reclamo portugués presentó un manifiesto a las Cortes pocos días después. Allí apelaba a la ley de Sucesión vigente impuesta por Felipe V para hacer una formal protesta y defender los derechos a la sucesión del príncipe heredero Francisco, primogénito del Rey Fernando IV (hermano de Carlos IV), en detrimento de los de Carlota. Posteriormente, Robertone entregó otro documento a las Cortes en el que reclamaba la Regencia para el Príncipe Real de las Dos Sicilias y anunciaba que éste estaba dispuesto a trasladarse a la Península para luchar contra los franceses ${ }^{29}$.

Ante la percepción de una opinión pública muy movilizada por los grupos liberales y de la formal demanda de la Corte de Nápoles, Sousa Holstein decidió aplazar el reclamo de la Regencia bajo el temor de que en ese clima político adverso se retrasara la promulgación de los derechos sucesorios. De allí en adelante ésta sería la estrategia del representante luso, que expresaba la del gabinete portugués, más interesado en garantizar la unidad de las dos coronas ibéricas y en proyectar su futuro a través de la descendencia de la infanta y D. João que en enviar a Carlota Joaquina a España a ocupar una Regencia provisional desde la cual podían malograrse los planes de máxima de los Braganza.

Quienes pretendían imponer el tema dinástico eran conscientes de que debían emprender una campaña de propaganda a mayor escala para presionar sobre los diputados. Aprovechaban para ello la libertad de imprenta decretada por las Cortes ${ }^{30}$. Así, mientras la Asamblea buscaba separar este debate de la deliberación pública, ya que todo lo referido a la ley de Sucesión como a las propuestas de regencias dinásticas fueron tratadas en sesiones secretas, el tema alcanzó amplia difusión. El embajador luso informaba que había hecho imprimir manifiestos destinados a circular entre los habitantes de la ciudad e incluso que llegó a pagar a periodistas locales para que publicaran sus recla$\operatorname{mos}^{31}$. Los agentes de la casa de Nápoles también desplegaban su acción de

27 TERNAVASIO, 2017.

28 Memoria del embajador portugués Pedro de Sousa Holstein, Cádiz, 6/11/1810, AHMI, II-POB-24.4.811-Ho.o 1-11.

${ }^{29}$ Nota del Encargado de Negocios de la casa real de las Dos Sicilias, Gerardo Robertone, Cádiz, 26/12/1810, AHMI, II-POB-24.4.811-Ho.o 1-11.

30 LA PARRA, 2005. CANTOS CASENAVE, DURÁN LÓPEZ y ROMERO FERRER, 2008

31 Sousa Holstein a Carlota Joaquina, Cádiz, 24/04/1811, AHMI, II-POB-24.4.811-Ho.o $1-11$.

Hispania, 2018, vol. LXXVIII, $\mathrm{n}^{\circ}$. 260, septiembre-diciembre, págs. 701-730, ISSN: 0018-2141, e-ISSN: 1988-8368 https://oi.org/10.3989/hispania.2018.016 
propaganda; según algunos testimonios repartían «impresos a balde por los cafés y sitios públicos» ${ }^{32}$.

La campaña se puso en marcha y fue especialmente álgida durante 1811 . Sousa Holstein enviaba a la Corte de Brasil los impresos que abordaban el tema, entre los que figuraban periódicos como La triple Alianza, la Gaceta de Cádiz, El Patriota en las Cortes, El Redactor General, El Conciso, Diario de la Tarde, Diario Mercantil de Cádiz. Incluía también una serie de folletos que debatían sobre las dos candidaturas de linaje: Conversación de un forastero con un vecino de la isla de León, escrito y distribuido entre los diputados en Cortes antes de su venta al público por el diputado realista Benito Ramón Hermida, uno de los más tempranos y férreos defensores de la candidatura de Carlota; Observaciones críticas acerca de la Conversación..., escrito por influencia del encargado de Negocios de Nápoles que impugnaba el precedente, atribuido a Andrés Moya y Luzuriaga; Aviso al público sobre las observaciones críticas acerca de la Conversación..., réplica de Hermida al folleto anterior; Opinión de un aldeano, folleto publicado en 1809 y reimpreso en 1811 que indicaba al príncipe heredero de las Dos Sicilias para ocupar la Regencia; La verdad de mal humor, papel escrito a favor de la Casa de Nápoles y atribuido a un amigo del marqués de Villafranca, diputado por Murcia ${ }^{33}$. El impreso anónimo citado al comienzo de este artículo, titulado Discurso sobre el peligro de la Patria, fue parte del paquete enviado a Río de Janeiro. De dicho impreso Sousa Holstein afirmaba lo siguiente: «al mismo tiempo que parece reconocerse la preferencia de los derechos de V.A.R de sucesión, se combate la idea de conferir la Regencia». El embajador se lo enviaba a la infanta porque, además de mencionar sus intereses, podía «ver los principales fundamentos del partido contrario a la Regencia, y cuán reñida es la guerra que ellos están haciendo a este respecto, más aún para ganar los sufragios de la opinión pública y de aquellos de las Cortes» ${ }^{34}$.

En el marco de esta guerra de papeles se destacan dos impresos. El que apareció bajo el título Conciliador, en el que se reproducía un manuscrito del Decano del Supremo Consejo de España e Indias, José Joaquín Colón ${ }^{35}$. Ubicado en el espectro contrario a las ideas liberales y más conocido por la censura que recibió su España vindicada publicada en 1811, Colón escribió

32 Fray Bernardo Díaz a Carlota Joaquina, Cádiz, 8/11/1811, AHMI, II-POB-12.8.811Dz.c 1-5.

33 Sousa Holstein a Carlota Joaquina, Cádiz, 24/04/1811, AHMI, II-POB-24.4.811-Ho.o $1-11$.

34 Sousa Holstein a Carlota Joaquina, Cádiz, 13/08/1811, AHMI, II-POB-24.4.811-Ho.o $1-11$.

35 Sousa Holstein destacaba que el mismo Colon le suministró el manuscrito y que él fue quien lo mandó a imprimir bajo el título Conciliador, AHMI, II-POB-24.4.811-Ho.o 1-11. 
aquel texto como respuesta crítica a una publicación de Pascual Bolaños Novoa, jurista y abogado de Cádiz, quien posteriormente fue designado por las Cortes para integrar el tribunal que debía enjuiciar a Colón por su España Vindicada. Bolaños, en su Disertación histórico-político-legal sobre la sucesión a la Corona de España, impresa y divulgada en 1811, defendía lo dispuesto por Felipe $\mathrm{V}$ de excluir a las mujeres de la sucesión y negaba validez a lo aprobado en las Cortes de 1789. Las últimas páginas de su Disertación estaban dedicadas a oponerse a los reclamos de Carlota Joaquina, tanto a la sucesión como a la Regencia, para presentar como candidato más idóneo al príncipe de Nápoles $^{36}$. Colón respondía a este escrito con una ácida réplica a sus postulados y exhibía una defensa cerrada de los derechos de la princesa de Brasil $^{37}$. En dicha defensa apelaba al concepto de «constitución» para aplicarlo a la antigua legislación y en este plano sometía a fuerte crítica la imposición de la ley Sálica en «aquel breve simulacro de Cortes» para sostener la legalidad de lo decidido en las Cortes de $1789^{38}$. Por supuesto que hubo otros escritos y réplicas, como la de un impreso que aseguraba «los muchos papeles que desde la instalación de las Cortes se han publicado en Cádiz y la Isla sobre la presente cuestión». El autor anónimo atacaba a Bolaños, instaba a abolir la ley de sucesión de 1713 para «purificar» de «nuestros códigos [...] éste y otros «francesismos» modernos que nos han traído a tan deplorable situación», y refutaba todos los argumentos que se oponían a los derechos de la infanta Carlota Joaquina ${ }^{39}$.

En casi todos los impresos que sostenían la candidatura napolitana se acusaba a Portugal de que sus planes se dirigían a consumar la unidad de las dos coronas ibéricas con el anhelo de sujetar a España. Se trataba de un argumento que apuntaba a dos frentes simultáneos: por un lado, buscaba alertar a los diputados españoles que pudieran apoyar la candidatura de Carlota Joaquina y capitalizar el secular recelo entre las dos potencias; por el otro, aspiraba a lograr el apoyo de Gran Bretaña y actualizar su temor a que dicha unión se concretara. La tenaz oposición de Inglaterra a los planes bragantinos respondía, en el marco del repentino cambio de alianzas internacionales, a la amenaza de que Portugal — su tradicional aliada y sobre la que ejercía una suerte de protectorado-, aprovechara la situación de acefalia española para avanzar con su plan dinástico. Un plan que implicaba, en cualquier formato que adop-

36 MORENO PASTOR, 2010.

37 José Joaquín Colón mantuvo correspondencia con Carlota Joaquina entre 1811 y 1813 , AHMI, I-POB-24.1.811-Col.c 1-4; I-POB-28.2.812-Col.c 1-2.

38 URQUIJO GOITIA y ÁLVAREZ-COCA GONZÁLEZ, 2012: 203.

39 Carta crítica sobre la Disertación histórico-político-legal..., 1811. Agradezco al evaluador anónimo de este artículo haberme puesto en conocimiento del impreso citado. 
tara, reunir a los dos más grandes imperios bi-oceánicos y romper el equilibrio internacional que Gran Bretaña pretendía arbitrar ${ }^{40}$.

En este sentido, los candidatos de linaje y sus operadores políticos debían convencer no sólo a la opinión pública local para influir en las Cortes sino también a la opinión internacional. A sabiendas que se trataba de asuntos muy sensibles, los argumentos de los napolitanos fueron cuidadosamente rebatidos por los impresos pro-carlotistas. En ellos se afirmaba que el enlace de las dos familias reales daría «a ambas monarquías un mundo político» con «una consistencia independiente», que Portugal no tenía intención alguna de dominar a España, que el plan bragantino era la mejor garantía de evitar las revoluciones e independencias de las colonias, y que la infanta había demostrado su compromiso con su tierra de origen ${ }^{41}$. Los operadores de la princesa aprovechaban también para distinguir las dos estrategias políticas en danza: se aclaraba que las pretensiones de Carlota se limitaban a reclamar los derechos sucesorios mientras que las de la majestad siciliana se extendían también a pedir la Regencia y la dirección del poder ejecutivo. En este último argumento, además de expresarse la estrategia de Portugal que prefería aplazar el debate por la Regencia, se apuntaba a despertar el encono de los liberales - recelosos de mantener en sus manos el control y la elección del ejecutivo provisional-, contra la casa de Nápoles.

Hasta aquí es posible advertir que el debate político era básicamente un debate jurídico, a la vez que los argumentos jurídicos invocados derrapaban rápidamente a la disputa política que imponía la nueva lógica instaurada con las Cortes. Una lógica que ya no hacía depender la razón de los contendientes - al menos de manera excluyente-, de la interpretación que los antiguos magistrados de la monarquía hicieran de las controvertidas leyes fundamentales, sino del número de votos que obtuvieran en la Asamblea. La nueva soberanía expresada a través de la representación política obligaba a todos a un trabajo de adaptación que implicó, por un lado, aprovechar los canales que ofrecía la libertad de imprenta para incidir en una opinión pública que ejercía una potente presión sobre quienes estaban en el recinto, y por el otro, a capitalizar vínculos interpersonales a través de una tarea capilar que entrañaba la creación de nuevas jerarquías políticas, tan necesarias a la hora de captar adhesiones. En este punto, los «operadores dinásticos» vivieron la paradoja de tener que defender la legitimidad tradicional de sus candidatos con los mecanismos e instrumentos que imponía la nueva legitimidad del número.

40 TERNAVASIO, 2015.

41 AHMI, II-POB-24.4.11- Ho.o 1-11. 


\section{LAS CANDIDATURAS «REALES»}

Si cruzamos el más conocido y estudiado debate en las Cortes con la red de contactos epistolares que en esos años tuvo como epicentro la candidatura de la infanta Carlota Joaquina se observa, en primer lugar, que dicha red involucró a miembros del partido realista en su vertiente más reaccionaria como moderada, a diputados americanos, y a diversos intermediarios y emisarios que triangulaban la correspondencia entre Río de Janeiro, Lisboa y Cádiz sin dejar de participar en la red los destinos americanos y Gran Bretaña ${ }^{42}$. En segundo lugar que, con el objetivo de alcanzar una aritmética de votos favorables en la Asamblea, la intervención de las legaciones extranjeras fue muy intensa. Se destaca, en este sentido, el firme y activo apoyo que tuvo Carlota del embajador portugués en Cádiz como el que le proporcionó el encargado interino de negocios de España en Lisboa, Pascual Tenorio y Ruiz de Moscoso. También fueron intensos los infructuosos trámites realizados para lograr el apoyo británico a través del ministro portugués en Londres, Domingo de Sousa Coutinho, hermano del ministro de Estado luso en Brasil y tío del embajador Sousa Holstein. En tercer lugar, que para lograr esa aritmética favorable de votos se apeló a todos los mecanismos posibles a los que conducía la nueva lógica parlamentaria y los «costos» de la política: gestionar privilegios y cargos para los que más trabajaron por la causa; intrigar para obtener entre diputados adeptos la presidencia de las Cortes cuando se discutían los proyectos sensibles; «distinguir» a quienes trabajaron en tal sentido, como ocurrió con la ley de Sucesión donde se sugirió privadamente «premiar al Obispo de Mallorca, a Larrazábal y al Obispo Prior de San Marcos de León por el celo que demostraron para superar las dificultades»; o «gratificar a los diputados» con «presentes», «auxilios», «promesas» e incluso con «dinero» constante y sonante para ganar sus adhesiones ${ }^{43}$.

De todos los contactos que, vía epistolar, se suceden y cruzan en esta etapa cabe subrayar en este apartado las misivas intercambiadas entre la infanta Carlota Joaquina y los diputados peninsulares que, dentro del grupo realista, lideraron la defensa de sus derechos sucesorios y a ocupar la Regencia en las Cortes. Se trata de Benito Ramón Hermida y José Pablo Valiente. Del primero, representante del Reino de Galicia, ya se ha mencionado su estrecha cola-

42 La correspondencia a la que hacemos referencia está dispersa en diferentes colecciones documentales impresas, en los archivos citados al comienzo de este artículo y en otros que, aunque no estén citados aquí, forman parte del corpus documental recogido y trabajado en la presente investigación. Entre los archivos no citados al comienzo cabe destacar: Archivo General de Palacio Real, Madrid; Archivo General de Indias, Sevilla; y Archivo General de la Nación, Buenos Aires.

43 AHMI, Cádiz, 26/12/1812, II-POB-24.4.811- Ho.o 1-11. 
boración a través de los impresos que publicaba a favor de la causa, a la que adhirió muy tempranamente en $1808^{44}$. Una vez electo diputado desplegó una intensa labor que comenzó en los días previos y continuó apenas se produjo la apertura de la Asamblea para sondear entre sus colegas las posibilidades de imponer a Carlota Joaquina en la futura Regencia, a sabiendas que el tema de su renovación sería tratado en las primeras sesiones ${ }^{45}$. Algunos testimonios dan cuenta de diversas reuniones, como el que proviene del alarmado embajador inglés en España, Henry Wellesley, quien en agosto de 1810 informaba a su gobierno que parecía existir un fuerte apoyo a la promoción de dicha candidatura. El embajador había sido informado de estas negociaciones por un emisario de un diputado electo, quien alegaba tener una mayoría en las Cortes para imponer a Carlota en la Regencia. Seguramente se trataba de un informe «inflado» en pos de lograr el apoyo del gabinete británico, el más reacio a aceptar tal propuesta. En este punto Gran Bretaña se mostró siempre inflexible, aunque recelaba profundamente de los ejecutivos republicanos ensayados en la Península. Así lo había expresado George Canning en octubre de 1808, ministro en ese momento de relaciones exteriores de Gran Bretaña, al sugerirle en una misiva a John Frere, por entonces embajador inglés en España, sobre la necesidad de «mantener el principio monárquico» y de desalentar las «innovaciones republicanas»o «cualquier tipo de gobierno por comités o por presidentes periódicos elegidos popularmente» ${ }^{46}$. Mientras Inglaterra cumplió con su compromiso de mantenerse ajena del debate sucesorio por tratarse — según afirmaba el mismo embajador Wellesley-, de un «asunto que consideraba puramente constitucional», no ocurrió lo mismo con el tema de la Regencia ${ }^{47}$.

Luego de estas conversaciones privadas, el tema fue tratado por primera vez en el recinto en la sesión secreta del 19 de octubre de 1810. En el momento en que se debatía la composición de la segunda Regencia, Hermida postuló «los derechos de la Sra. Infanta Carlota ${ }^{48}$. La rápida movida de los principales promotores de la princesa no obtuvo la respuesta que temía el embajador británico en su informe. La moción de Hermida fue diferida. Luego de la presentación en las Cortes de las memorias ya citadas de los ministros luso y napolitano en noviembre y diciembre, respectivamente, que desataron la controversia dinástica en los papeles públicos, los grupos realistas que propulsa-

44 TERNAVASIO, 2013.

45 Véase el testimonio de Joaquín Lorenzo Villanueva, titulado Mi viaje a las Cortes, s/f, Biblioteca Virtual Miguel de Cervantes, 20.

46 Canning a Frere, Londres, 5/10/1808, MD, t. III: 240.

47 AHMI, II-POB-24.4.811-Ho.o 1-11.

48 Diario de las sesiones secretas de las Cortes Generales Extraordinarias de la Nación Española, Biblioteca Virtual Constitución 1812, Centro de Estudios Constitucionales (en adelante DSS), 19/10/1810: 27. 
ban la candidatura de Carlota a la Regencia quedaron subsumidos a la estrategia de aplazar dicho debate por la que trabajaba Sousa Holstein, sin duda muy influyente en el sector antireformista según revela la correspondencia del plenipotenciario ${ }^{49}$.

Sin embargo, el plan de aplazar el reclamo de la Regencia en pos de afianzar el voto de los derechos sucesorios no siempre pudo disciplinar a sus más cercanos colaboradores. Tal fue el caso del diputado por Sevilla, José Pablo Valiente, quien en el mes de julio de 1811, en ocasión de una de las tantas crisis entre la Regencia y las Cortes, creyó oportuno presentar una moción destinada a que Carlota Joaquina presidiera un Consejo de Regencia de tres miembros ${ }^{50}$. Además de ser fustigado por el paladín liberal, el Conde de Toreno, desató el enfado del principal operador luso que no lograba controlar a su propia tropa:

Hay poderosos motivos para creer que esta proposición en sí misma tan deseable y hecha con las mejores intenciones era inoportuna en este momento y contribuirá sino a estorbar, al menos atrasar la Declaración de los Derechos de VAR a la Sucesión, excitando el susto de todos aquellos que o por prejuicios o por intereses particulares serían opuestos a la opinión de la Regencia; y recién después de declarada la Sucesión no encontrar medios para estorbar ${ }^{51}$.

La propuesta, aunque debatida, no tuvo eco y derivó en un violento incidente el 26 de octubre. El acta de la sesión secreta de ese día describe que en medio de un clima de «fermentación», el diputado Valiente fue agredido por una movilización callejera ${ }^{52}$, y según algunos testimonios el gran alborozo se armó porque «salieron pidiendo su cabeza por traidor a la patria sólo por defender los derechos de VAR ${ }^{53}$. El diputado logró escapar del atolladero, abandonó su banca y se retiró a Tánger. Desde allí le escribió a la princesa instándola a que su esposo interceda frente al gabinete inglés, por ser éste junto a los liberales los principales enemigos a concretar sus planes ${ }^{54}$. Ésta fue la última intervención a favor de una Regencia dinástica en la etapa que precedió a la votación por la ley de Sucesión.

49 ANTT, Fondo Casa Palmela 1286/1989, liv.117: Informações sobre a sucessão ao trono de Espanha, PT/TT/ Fondo Casa Palmela /C-A/1/117.

50 DSS, 16/07/1811: 347.

51 Sousa Holstein a Carlota Joaquina, Cádiz, 26/07/1811, AHMI, II-POB-24.4.811-Ho.o $1-11$.

52 DSS, 26/10/1811: 450. Testimonio de Joaquín Lorenzo Villanueva, titulado Mi viaje a las Cortes, s/f, Biblioteca Virtual Miguel de Cervantes, 288. Dz.c 1-5.

53 Fray Bernardo Díaz a Carlota Joaquina, Cádiz, 7/11/1811, AHMI, II-POB-12.8.811-

${ }^{54}$ José Pablo Valiente a Carlota Joaquina, Tánger, 19/02/1812, AHMI, II-POB19.2.812-Vali.c. 
La campaña por la ley de Sucesión fue, sin duda, exitosa para los bragantinos. La imagen que pintaba el embajador luso sobre el mapa que exhibía el fragmentado escenario gaditano revela las «dificultades de tratar con 150 personas diferentes a las que había que persuadir» $\aleph^{55}$. El cuadro de adhesiones y oposiciones que delineaba en sus misivas expresa una visión de los partidos que sigue la lógica de una diputación que, más allá de las divisiones ideológicas, se posicionaba según los proyectos en danza y la versatilidad que caracterizó a las tendencias allí presentes ${ }^{56}$.

A pesar de las dilaciones y obstáculos que pusieron los liberales para su tratamiento, las Cortes aprobaron en la sesión del 21 de diciembre de 1811 la derogación de la ley Sálica con una votación nominal que obtuvo una amplia mayoría: 126 votos contra 2057. A fines de febrero de 1812 quedaron aprobadas las cláusulas sobre la sucesión a la Corona en las que la infanta Carlota Joaquina quedaba explícitamente incorporada mientras se excluyó de la línea sucesoria al infante Francisco de Paula, a la infanta María Luisa, y sus respectivas descendencias. La Casa de Nápoles había sido derrotada.

Sin embargo, aquella correlación de fuerzas que se expresó en el voto de la ley de Sucesión no se replicó pocos días después de derogada la ley Sálica. Con el objeto de sacar provecho de la crisis en la que se hallaba la segunda Regencia, el diputado conservador Alonso María de Vera y Pantoja, de Extremadura, elevó la propuesta de formar a la brevedad una Regencia presidida por persona real y que se disolvieran las Cortes en el espacio de un mes. Durante cuatro sesiones hubo violentas discusiones en el recinto y, en este caso, la moción fue derrotada por 93 votos contra 33. En ese clima de confrontación los liberales no perdieron tiempo y, a propuesta de Argüelles, dejaron establecido que durante la ausencia de Fernando VII no puede estar al frente del gobierno de la Regencia «ninguna persona real» ${ }^{58}$.

Frente a la pregunta de por qué las Cortes aceptaron mayoritariamente la ley de Sucesión y fue la Regencia real la que mayores reticencias y conflictos desató en los diferentes círculos políticos, podemos avanzar una respuesta rápida a la primera parte del interrogante. Si bien los liberales buscaron postergar lo más posible el tratamiento de la ley de Sucesión (a través de sucesivas consultas que hizo sospechar a varios de una alianza táctica con la rama napolitana), la relevancia y delicadeza del asunto indica que hubiera resultado

55 Sousa Holstein a Carlota Joaquina, Cádiz, 24/04/1811, AHMI, II-POB-24.4.811-Ho.o $1-11$.

56 Las divisiones internas dentro de las Cortes de Cádiz han sido objeto de diversas clasificaciones. Para un detallado estado de la cuestión sobre el tema véase BREÑA, 2006.

57 DSS, 21/12/1811: 506-509.

58 Véase el testimonio de Joaquín Lorenzo Villanueva, titulado Mi viaje a las Cortes, s/f, Biblioteca Virtual Miguel de Cervantes: 306-309. 
muy difícil contrarrestar jurídicamente el descrédito de la ley impuesta por Felipe V, considerada una ley «extranjera» que había modificado el derecho tradicional español. Pero me interesa detener el análisis en la segunda premisa de la pregunta: ¿qué dilemas expresaron los conflictos por la Regencia dinástica? Aceptar, sin más, la obvia respuesta de que sus sucesivos fracasos se debieron a la existencia de una mayoría liberal que dominaba la Asamblea impide interrogarse sobre las posibles razones de las estrategias y correlaciones de fuerzas que, respecto de este tema, revelaron los grupos representados en las Cortes y de aquellos que ejercían presión desde afuera del recinto e, incluso, de las propias fronteras de la metrópoli.

Entre fines de 1811 y comienzos de 1812, el regreso de Fernando VII y de su hermano, el infante Carlos María Isidro, segundo en la línea de sucesión y ambos cautivos en Francia, era una hipótesis plagada de incertidumbre. Carlota Joaquina era ahora la candidata que continuaba en dicha línea y entre quienes votaron favorablemente la abolición de la ley Sálica había, sin duda, muchos que estaban lejos de desear tal desenlace. Sin embargo, era una hipótesis que podía quedar en suspenso hacia un futuro incierto mientras que presidir el ejecutivo provisorio ponía en juego el presente de esa nueva criatura que era la Constitución y el propio poder constituyente y legislativo.

Para los liberales, tanto en su versión más radical como moderada, la Regencia real significaba una amenaza sobre la que advertía el embajador luso. Así lo hizo pocos días después de votarse la abolición de la ley Sálica cuando reconocía «los celos que tienen de que todo sea una conspiración contra la nueva Constitución, principalmente después del manifiesto de Lardizábal y de la suspensión del Consejo de Castilla; tienen miedo de que el Consejo se vengue algún día por la afrenta ${ }^{59}$. Y volvía a advertir sobre el mismo asunto apenas se aprobó la carta constitucional. Para contrarrestar el temor de los liberales, Sousa Holstein le sugería a la infanta mantener la mesura y elevar una nota a la Regencia «con expresiones de afecto y agradecimiento a las Cortes para lograr un mejor efecto» en pos de «remover la idea promovida por el Partido Liberal de que la entrada de una persona real a la Regencia sería la ruina de la Constitución» ${ }^{60}$.

Dicho temor se fundaba en la convicción de que la presencia de un Borbón en el gobierno capitalizaría la deferencia que emanaba de su linaje y dotaría de unidad a los sectores realistas que, por cierto, no constituían un grupo homogéneo ni poseían un programa político unificado para enfrentar a la mayoría liberal que, vale recordar, tampoco conformaba un grupo homogéneo. La debilidad que padecían los realistas derivaba, precisamente, de la ausencia

59 Sousa Holstein, 10/01/1812, AHMI, II-POB-8.1.812-Ho.o 1-3.

60 Sousa Holstein a Carlota Joaquina, Cádiz, 27/03/1812, AHMI, II-POB-5.3.812-Ho.o $1-2$.

Hispania, 2018, vol. LXXVIII, nº. 260, septiembre-diciembre, págs. 701-730, ISSN: 0018-2141, e-ISSN: 1988-8368 https://oi.org/10.3989/hispania.2018.016 
del rey pero también de no compartir la misma visión de la monarquía ${ }^{61}$. De hecho, entre los dos diputados que lideraron los reclamos bragantinos se colaban estas diferencias que se tradujeron en las dos estrategias políticas aquí señaladas. Mientras Benito Hermida venía propulsando desde 1808 la unidad de las dos coronas ibéricas y por ello se acogió a no poner en riesgo el plan de ver primero reconocidos los derechos sucesorios de Carlota, José Pablo Valiente, del sector más ultraconservador y absolutista, admitía en su correspondencia con la infanta «ser uno de los más decididos por la observancia de la antigua Constitución de España sin más reformar que en el punto de Cortes mal definido en las leyes». Valiente sostenía que las Cortes gaditanas «son obra de la necesidad y el conflicto», y que su objeto debía estar «reducido a crear un gobierno provisorio a cargo de hombres presididos por VAR como Infanta de España» y a «perfeccionar la Constitución de esta monarquía sin alterarla y disolverse el Congreso» ${ }^{62}$.

La calurosa adhesión al absolutismo de la princesa instalada en Brasil era muy conocida y no colaboraba a despejar las amenazas que veían en su candidatura los grupos más radicales. Así lo había demostrado Carlota en su correspondencia dirigida a las Cortes, en la que deliberadamente se negaba a darles el tratamiento de «Majestad»; un gesto que había molestado mucho a los diputados liberales. El recelo a que su presencia supliera simbólicamente la falta del referente regio y catalizara desde el interior del ejecutivo provisorio una acción política capaz de anular el proceso constituyente iniciado en 1810 explica la siempre encrespada oposición que exhibieron los liberales a permitir que la princesa ocupara la Regencia, tanto en la etapa que precedió a la sanción de la Constitución como en la que le continuó.

En ese escenario, ya se ha demostrado en diversos estudios que la representación americana, más allá de la común defensa de un nuevo estatuto para América, estuvo atravesada por una mayoría que apoyó a la tendencia liberal, tanto en su versión moderada como más radical y por una minoría ultraconservadora, en un horizonte general signado por oscilantes posiciones ${ }^{63}$. Tales oscilaciones quedaron al desnudo particularmente frente al tema que nos ocupa. Si bien casi todos los diputados americanos votaron a favor de la abolición de la ley Sálica, algo muy distinto era promover o apoyar una Regencia de persona real. Antes de sancionarse la Constitución, el único representante americano que promovió en solitario una moción para llamar a la princesa a ocupar la Regencia en la Península fue el diputado Lisperger, supletorio por

\footnotetext{
61 MARTÍNEZ SOSPREDA, 2012.

62 José Pablo Valiente a Carlota Joaquina, Cádiz, 28/10/1811, AHMI, I-POB-20.10.811Vali.c.

63 BERRUEZO, 1986. CHUST, 1999. RIEU-MILLAN, 1990.
} 
Buenos Aires, nunca reconocido por el gobierno revolucionario rioplatense ${ }^{64}$. Pocos días después, el diputado por Santo Domingo, Álvarez de Toledo, propuso acelerar la sanción de la Constitución y una vez aprobada llamar «al trono un Príncipe de la sangre real, para regir la monarquía provisionalmente hasta la venida del Sr. Don Fernando VII $\rangle^{65}$. Pero en este caso el diputado era un claro promotor de la candidatura napolitana.

Más allá de los mapas partidarios y de las adhesiones que contabilizaban los operadores de las candidaturas en su correspondencia privada, de la red epistolar que tuvo por centro a la infanta Carlota se deduce que algunos diputados americanos apoyaron explícitamente sus planes. Tales los casos de los representantes por Perú, Vicente Morales Duares, Blas Ostolaza y Ramón Feliú - quienes contaban en su tierra de origen con el apoyo del carlotista José Baquíjano-, y del diputado ultraconservador por Puebla, Antonio Joaquín Pérez ${ }^{66}$. Estos apoyos, como afirma Rieu Millan, podían responder a razones similares a las de los realistas, pero sobre todo a razones particulares americanas ${ }^{67}$. La posibilidad de tener un «gobierno menos metropolitanista» — según indica Eduardo Martiré_ - ${ }^{68}$, fue una demanda que supieron capitalizar los operadores carlotistas de la Península: la situación de que «V.A.R. reside en América y si se muda a Europa defenderá los intereses de ellos» fue cuidadosamente utilizada a la hora de conseguir sus votos ${ }^{69}$.

En cualquier hipótesis, lo que exhibió la etapa que se cierra con la sanción de la Constitución fueron los dilemas de disputar simultáneamente el presente y el futuro de esa nueva criatura que se encarnaba en el poder ejecutivo de una monarquía constitucional sin monarca. Los propulsores de una candidatura de linaje habían proyectado moderar, frenar o abortar el proceso constituyente sin éxito, y sólo una fracción de los partidos dinásticos había logrado su objetivo. Los liberales temían, con razón, la insistencia de éstos por alcanzar el ejecutivo provisorio porque todos entendían que era una llave fundamental para gestionar la política, aunque siempre bajo el control de la mayoría de la Asamblea. La condición insegura e inestable del poder ejecutivo quedaba pues en evidencia al presentarse como emblema de unidad del gobierno y padecer la devaluada dignidad de derecho que tenía frente a la representación que emanaba del poder constituyente y legislativo que hablaba en nombre de la «nación española» de ambos hemisferios.

64 DSS, $15 / 02 / 1811$.

65 DSS, 22/03/1811.

${ }^{66}$ La correspondencia de estos personajes con la infanta Carlota se encuentra en AHMI.

67 RIEU-MILLAN, 1990: 363.

68 MARTIRÉ, 2009: 131-132.

69 AHMI, II-POB-8.1.812-Ho.o 1-3. 


\section{ENTRE UN «GOBIERNO INTERINO» Y UN «GOBIERNO PERPETUO»}

La derogación de la ley Sálica y la aprobación de la ley de Sucesión en la nueva carta constitucional de 1812 significaron un momento de inflexión en las estrategias políticas, argumentos vertidos y alianzas que encarnaron quienes pugnaban por imponer una Regencia dinástica. Con Carlota Joaquina confirmada como sucesora al trono, y al calor de la cambiante situación que experimentaba la Península, el debate desplegado hasta ese momento, que oponía el reclamo de «unidad y fortaleza» a la situación de «fragmentación y debilidad» del gobierno, mutó y se entrelazó con una nueva oposición: instaurar un «gobierno perpetuo» para acabar con el «gobierno interino» de las regencias colegiadas y electivas en manos de particulares.

Donde más claramente se enunció este argumento fue en el texto escrito a mediados de 1812 - en el marco de una nueva crisis de la Regencia-, por el ultraconservador Tadeo Francisco Calomarde, titulado Último recurso de la nación española para conservar su existencia política ${ }^{70}$. El autor tenía previsto publicarlo pero decidió esperar una ocasión más conveniente para que la Regencia no lo considerara un ataque en su contra. No obstante, el embajador luso y los miembros del partido realista que buscaban reflotar ahora el plan de trasladar a la infanta para encarnar una Regencia, se encargaron de difundirlo y de hacer propaganda a su favor. Calomarde mantenía contactos epistolares con Carlota Joaquina desde 1811 y en sus misivas la informaba de los debates suscitados en las Cortes alrededor de su candidatura ${ }^{71}$.

En su extenso escrito, el autor pasaba revista por diversos temas - históricos, jurídicos y políticos-, para desplegar su argumento central. El punto de partida del argumento recuperaba la crítica de «no haber tenido un gobierno cual exigía nuestra situación actual»; la experiencia de dos años de regencias débiles había conducido a la anarquía, la indisciplina y la desobediencia. Pero el diagnóstico aquí se atribuía a la condición «interina» del gobierno. En tal sentido se ocupaba de reconstruir la larga historia de las regencias por minoridad del rey en la monarquía española y distinguía entre aquellas que habían causado desórdenes e indolencia por la debilidad de los regentes, de las «poquísimas Regencias que no han sido desgraciadas»; a saber, las que habían tenido como regentes del reino a los parientes del rey más próximos a heredar la Corona ${ }^{72}$. Su propuesta, entonces, era hacer «cesar en lo posible la interinidad del gobierno; autoricemos al próximo sucesor de nuestros Prínci-

70 Último recurso de la Nación española para conservar su existencia política, deducido de la historia de nuestras regencias, Cádiz, Imprenta de la Concordia, 1813, BN.

71 AHMI, I-POB-1.3.812-Calo.c 1-3.

${ }^{72}$ Último recurso de la Nación española para conservar su existencia política, deducido de la historia de nuestras regencias, Cádiz, Imprenta de la Concordia, 1813: 42, BN. 
pes cautivos» ${ }^{73}$. Esto significaba crear un «gobierno perpetuo» bajo la hipótesis de que los príncipes no regresarían: «es tan en vano esperar que [Francia] nos restituya voluntariamente a nuestro deseado Rey y su hermano, como el quitárselos por la fuerza» ${ }^{74}$.

A partir de esta torción argumentativa, regresaba sobre los lugares comunes invocados hasta el momento - como la «veneración y el respeto», la «fuerza del hábito» y la «energía y autoridad» que implicaría elegir una persona real al frente del Gobierno-, reforzados, luego de la constitucionalización de los derechos dinásticos de la infanta, por las ventajas «incomparablemente mayores si ésta es inmediata sucesora $\rangle^{75}$. A la objeción del peligro de «usurpación» del trono que desembocó en la resolución de las Cortes del 1 de enero de 1812 de que la Regencia no fuera ocupada por persona real para evitar el ascenso de la inmediata sucesora, le oponía que «los particulares son tanto o más capaces de este crimen que las personas reales» ${ }^{76}$. Y a la objeción de que las Cortes ya se habían expedido sobre este punto respondía con la nueva lógica sobre la que se montaba ahora el orden legal. El decreto aludido podía ser revocable y reemplazado rápidamente a través de la aritmética de los votos: «nunca puede tener la autoridad de cosa juzgada para el efecto de no poderse abrir el juicio siempre que se crea conveniente» ${ }^{77}$. En este punto dejaba en evidencia la política legislativa de aquellas Cortes, cuya selectiva acción derogatoria se expresaba en un constante diálogo con el pasado y en una política de inclusión-exclusión que miraba al presente ${ }^{78}$.

Finalmente, pasaba revista por las ventajas que tendría designar a Carlota Joaquina al frente de la Regencia. Además de dotar de unidad al pueblo «que está fluctuando entre parcialidades, bandos y disensiones bajo un gobierno aristocrático o democrático» ${ }^{79}$, destacaba sus condiciones personales para el mando, desestimaba el lugar común que la descalificaba por su condición de mujer, y afirmaba que era una «prenda de paz» frente a las insurrecciones

73 Último recurso de la Nación española para conservar su existencia politica, deducido de la historia de nuestras regencias, Cádiz, Imprenta de la Concordia, 1813: 52, BN.

74 Último recurso de la Nación española para conservar su existencia política, deducido de la historia de nuestras regencias, Cádiz, Imprenta de la Concordia, 1813: 54, BN.

75 Último recurso de la Nación española para conservar su existencia política, deducido de la historia de nuestras regencias, Cádiz, Imprenta de la Concordia, 1813: 54-55, BN.

76 Último recurso de la Nación española para conservar su existencia política, deducido de la historia de nuestras regencias, Cádiz, Imprenta de la Concordia, 1813: 102, BN.

77 Último recurso de la Nación española para conservar su existencia política, deducido de la historia de nuestras regencias, Cádiz, Imprenta de la Concordia, 1813: 106, BN.

78 GARRIGA y LORENTE, 2007: 38.

79 Último recurso de la Nación española para conservar su existencia política, deducido de la historia de nuestras regencias, Cádiz, Imprenta de la Concordia, 1813: 56, BN. 
americanas donde la infanta estaba demostrando una férrea voluntad de intervenir de manera directa para defender la integridad de la monarquía.

Este último punto no era un detalle menor en el momento en el que se debatía la crisis de la Regencia, con una América insurreccionada y con el fracaso que la mediación inglesa estaba exhibiendo. De hecho, este escrito se difundió entre julio y septiembre de 1812, cuando la batalla para colocar a la infanta a la cabeza de la Regencia fue especialmente retomada por algunos diputados americanos que, en alianza con los grupos realistas, la presentaron como prenda de conciliación con las regiones que se hallaban en plena insurgencia. Si hasta allí los avatares carlotistas en América habían afectado básicamente a las regiones del Atlántico Sur, en aquel momento fue la Nueva España la que tomó la iniciativa, en gran parte acicateada por haber sido confirmada la infanta como la sucesora legítima y constitucional al trono vacante ${ }^{80}$. En esas circunstancias, asediadas las autoridades novohispanas por los movimientos insurgentes, el secretario interino del virrey Venegas elevó una propuesta para que la princesa heredera del trono fuese elegida regente: «sería un corte decisivo para cortar esta rebelión el que viniese a establecer su Corte en México mientras la Península no ofreciera seguridad a su persona, sin perjuicio de que España siguiese gobernada por una Regencia como lo está Portugal ${ }^{81}$. Convertir a ciudad de México en una suerte de Río de Janeiro hispana era una alternativa de conciliación que no pasará desapercibida entre los diputados americanos en las Cortes ni por el embajador luso allí apostado.

A fines de agosto, Sousa Holstein reflotó la nota del secretario del virrey novohispano, y le escribía a la infanta para expresarle su convicción de que en estos términos lograría el apoyo de la mayoría de diputados americanos y que «venía trabajando con actividad para que éstos fuesen auxiliados por un suficiente número de diputados europeos» ${ }^{82}$. El equilibrio en la correlación de fuerzas respecto de este tema puntual había cambiado en relación a la etapa precedente: eran ahora los americanos los que tomaban la iniciativa, liderados por los representantes más cercanos a la infanta según indica la correspondencia intercambiada, secundados por los grupos conservadores de la Península. El plenipotenciario era consciente, en este punto, de los intereses divergentes que anidaban unos y otros. Mientras que para los primeros era una gran ocasión de americanizar la monarquía, los europeos se mostraban «recelosos —informaba Sousa Holstein-, de que la proposición de los americanos guarden segundas intenciones, como el de establecer desde ahora la residen-

80 TERNAVASIO, 2015.

81 Citado en PIMENTA, 2003: 122.

82 Sousa Holstein a Carlota Joaquina, Cádiz, 31/08/1812, AMRE, Legación en Cádiz (1810-1813).

Hispania, 2018, vol. LXXVIII, $\mathrm{n}^{\circ}$. 260, septiembre-diciembre, págs. 701-730, ISSN: 0018-2141, e-ISSN: 1988-8368 https://doi.org/10.3989/hispania.2018.016 
cia del gobierno en América» ${ }^{83}$. El plan intentó llevarse a cabo en octubre, cuando se discutía la elección de un regente para cubrir la vacante que había dejado la renuncia del conde de La Bisbal, supuestamente partidario de la infanta según Joaquim Severino Gomes, nuevo encargado de negocios de Portugal que reemplazó a Sousa Holstein, destinado a Londres por orden del gabinete luso ${ }^{84}$.

Los acontecimientos que continuaron son conocidos y el diputado por Valencia, Joaquín Lorenzo Villanueva, ha dejado un detallado testimonio de lo ocurrido. Sólo basta decir que la iniciativa en las Cortes la presentó el diputado por Perú, Ramón Feliú, quien solicitó leer un escrito donde se proponía la candidatura de la princesa para presidir la Regencia como el único medio que quedaba para pacificar América luego del reciente fracaso de la mediación británica. A pesar de las reticencias de los grupos conservadores a que el plan incluyera el traslado de la infanta a México antes de seguir viaje a España, el diputado peruano siguió adelante con ese plan. Carlota debía permanecer por unos meses en Nueva España para «restablecer allí la paz y el orden» y luego dirigirse a la Península para «presidir la Regencia del reino» ${ }^{85}$. La propuesta desató un escándalo con la virulenta oposición de los liberales que argumentaron la contravención de lo acordado por las Cortes meses atrás. Argüelles «declaró e invitó a los de su partido a revolucionar al pueblo si la propuesta de Feliú se admitía», según el testimonio del nuevo embajador luso ${ }^{86}$. Todo culminó con el retiro por parte de Feliú de su propuesta y con la elección de Juan Pérez Villamil como regente.

Con este nuevo fracaso, los partidarios de una Regencia real tenían la expectativa de que el «gobierno salga de Cádiz donde los liberales esparcen veneno» y consiguen «vivas en las tribunas e insultan a los que se quieren oponer a sus maquiavélicas ideas» ${ }^{87}$. La imagen que percibían era la de un recinto parlamentario sitiado, y por ello riesgoso, como había demostrado el episodio del diputado Valiente y el más reciente desatado con la moción del representante por Perú. Tal vez por esta razón decidieron dosificar el uso de publicaciones impresas para difundir sus planes y abocarse a una labor silenciosa, a través de contactos interpersonales, con el objeto de aunar más voluntades en las provincias peninsulares donde tenían agentes trabajando.

En 1813 el tema volvió a actualizarse. Durante ese año, el impulso de las fuerzas reformistas más radicales comenzó a agotarse. De hecho, en las elec-

83 Ofício reservado, Cádiz, 7/09/1812, AMRE, Legación en Cádiz (1810-1813).

84 Gomes a Carlota Joaquina, Cádiz, 22/09/1812, AHMI, II-POB-22.9.812-Gmes.o 1-3.

85 Véase el testimonio de Joaquín Lorenzo Villanueva, titulado Mi viaje a las Cortes, s/f, Biblioteca Virtual Miguel de Cervantes, 402-403.

86 Gomes a Carlota Joaquina, Cádiz, 3/10/1812, AHMI, II-POB-22.9.812-Gmes.o 1-3.

87 Gomes a Carlota Joaquina, Cádiz, 3/10/1812, AHMI, II-POB-22.9.812-Gmes.o 1-3. 
ciones para las Cortes ordinarias del verano de dicho año la correlación de fuerzas resultantes no parecía estar inclinada a las novedades ${ }^{88}$. La correspondencia aquí trabajada da cuenta, en este sentido, de los intentos que hicieron los operadores de una Regencia dinástica para que «los diputados nombrados para nueva Corte sean hombres probos y adictos a los intereses de VAR» ${ }^{89}$.

En ese cambiante contexto, un nuevo desgaste de la Regencia habilitó a que en el mes de marzo corrieran fuertes rumores de que se presentaría una vez más la propuesta del traslado de Carlota, ahora liderada por el diputado por Canarias, Antonio José Ruiz de Padrón. Este diputado, que no se identificaba con el sector más conservador, había escrito un extenso manifiesto para fundamentar su moción en el que regresaba sobre los clásicos argumentos vertidos hasta el momento y que fue entregado a uno de los secretarios de las Cortes para leerse en una de las sesiones. Apenas se divulgó la noticia, la «fermentación» se hizo dueña de «las plazas y corrillos de Cádiz» según confesaba el mismo autor ${ }^{90}$. El manifiesto no llegó a leerse ni a presentarse la moción, y quedó conformada la cuarta y última Regencia de tres miembros, en la que ahora se integraba al único individuo de la familia Borbón que se hallaba en la Península para presidirla: el cardenal Luis María de Borbón y Villabriga, arzobispo de Toledo e hijo de Luis de Borbón, hermano de Carlos III, al que habían recurrido los sectores más conservadores entre 1808 y 1809 para ocupar una Regencia dinástica. Su inclusión puede parecer a primera vista una forma de negociar con el partido realista en el marco de una de las más profundas crisis de la Regencia. No obstante, la rápida redacción de un nuevo reglamento para el ejecutivo provisorio parece indicar —según demuestra Flaquer Montequi-, una sensible merma del poder efectivo del Consejo de Regencia ${ }^{91}$.

En los meses siguientes, las fricciones entre liberales y realistas se acrecentaron frente al previsible regreso del Rey. Las Cortes Generales y Extraordinarias habían llegado a su fin en el mes de septiembre y las Cortes Ordinarias abrieron sus sesiones en octubre de 1813, primero en Cádiz para trasladarse luego a Madrid a mediados de enero de 1814. A esa altura, los hechos se habían precipitado: Fernando VII fue liberado por Napoleón y regresaba a España acompañado por su hermano, el infante Carlos.

En el ínterin, las redes carlotistas no se llamaron a silencio. En ese contexto reapareció el manifiesto ya mencionado de Ruiz Padrón, escrito en marzo de 1813 y ahora impreso en Madrid, en el que polemizaba frontalmente con los liberales. En la Advertencia que el autor le agregó a su texto, en ocasión

88 BREÑA, 2006: 128.

89 Gomes a Carlota Joaquina, Cádiz, 4/11/1812, AHMI, II-POB-22.9.812-Gmes.o 1-3.

90 Dictamen de Don Antonio José Ruiz de Padrón..., 1814.

91 FLAQUER MONTEQUI, 2003: 61. 
de ser publicado casi un año después, adaptaba su proposición a la incertidumbre del momento, cuando Fernando VII estaba en camino y era todavía una incógnita la política que adoptaría una vez restaurado. Al referirse a su dictamen anterior, en el que postulaba que la única y mejor candidata a la Regencia era Carlota Joaquina, afirmaba que los motivos que tuvo para hacerlo «subsisten aún por desgracia, y acaso son en la actualidad más urgentes y poderosos $\rangle^{92}$. ¿Cuáles eran esos motivos? El futuro derrotero de la monarquía constitucional.

El último intento de colocar en la Regencia a la sucesora al trono para sustituir la de signo liberal presidida por el cardenal de Borbón, quien había recibido instrucciones de las Cortes de no reconocer «por libre al Rey» hasta que éste no prestara juramento en el seno del Congreso Nacional según lo prescripto por la Constitución vigente, ya no apuntaba a superar la condición de gobierno interino sino a garantizar el regreso a un gobierno perpetuo, pero de signo absolutista. Como sabemos el plan fracasó y no fue necesario para los objetivos que se proponía. El rey restauró el absolutismo con el decreto del 4 de mayo expedido en Valencia y actuó en consecuencia una vez instalado en Madrid.

\section{REFLEXIÓN FINAL}

El interregno había llegado a su fin como también la experiencia constitucional gaditana. Una experiencia que, además de mostrar heterodoxia frente a los lenguajes constitucionales que circulaban en la época, debió enfrentar en sus «plasmaciones prácticas» las «cuestiones inseguras y problemáticas» anunciadas por Clavero-, que derivaron tanto en su peculiar condición de gobierno interino como en la dificultad por conciliar la tradición con el nuevo idioma de división de poderes. El recelo hacia el poder ejecutivo en general, y en especial hacia un ejecutivo monárquico, como habían exhibido los revolucionarios franceses y tal como demostraron los liberales doceañistas, no implicaba poner en duda la solidez de las creencias monárquicas en el mundo hispánico. Dicho recelo no era ajeno al clima de época que postulaba limitar el poder, ni al influjo del nacionalismo historicista que buscaba rescatar el papel de las viejas Cortes para denostar el denominado «despotismo ministerial», ni al acontecer político vivido en el pasado reciente, con una monarquía desacreditada que había renunciado a la Corona en los tristemente célebres episodios de Bayona ${ }^{93}$. Pero tampoco era ajeno a la condición inestable que encerraba el misterio del poder ejecutivo.

\footnotetext{
92 Dictamen de Don Antonio José Ruiz de Padrón..., 1814: 7-12.

93 VARELA SUANZES-CARPEGNA, 1987.
} 
En el marco de la brutal transformación que implicó pasar de un Antiguo Régimen dominado por la creencia de un orden divino, y por lo tanto natural e indisponible, a otro que lo hacía derivar de convenciones humanas nacidas del nuevo poder constituyente y legislativo, el concepto de «poder ejecutivo» fue del todo novedoso en la historia del pensamiento político. Pierre Manent, desde el campo de la teoría política, subraya este dato y, en sintonía con el planteo de Clavero, cuestiona la «impresión de claridad» que exhibe la interpretación clásica sobre el origen y función de los dos poderes que remite habitualmente a Locke y Montesquieu, quienes — como es bien sabido-, reflexionaron a partir de la observación del conflicto entre el Rey de Inglaterra y la Cámara de los Comunes. El autor destaca que existe una desigual «dignidad» en la naturaleza de ambos que encierra el dilema del poder ejecutivo moderno. Mientras el legislativo se ancla en una dignidad de «derecho», el ejecutivo debe su existencia a una necesidad de «hecho» y por ello «el sentido y la legitimidad de éste son 'inseguros' — dice el autor-, porque la legitimidad política moderna se funda en la representación y porque el terreno 'natural' de la representación es el cuerpo legislativo» ${ }^{94}$.

El debate que confrontó a los ejecutivos republicanos creados en el seno de una monarquía constitucional, que nacía con $-\mathrm{y}$ como producto de - un rey ausente, con el tradicional principio de linaje, expresa, en el fondo, un común horizonte de reserva de desconfianza política que atravesó a todos los actores del momento. La devaluada dignidad de derecho del poder ejecutivo moderno y la también devaluada dignidad histórica y mística de la figura monárquica dejaban abierta la pregunta acerca de quién podía pretender representar a los individuos y los cuerpos de la sociedad en su condición política. Como sabemos, este fue un dilema para todos los órdenes políticos nacidos en aquellos convulsionados tiempos revolucionarios y que afectó tanto a las monarquías constitucionales como a los recientes sistemas republicanos. El común desafío, sin embargo, consistía en superar la dificultad que nacía de la disputa por definir quién encarnaba ahora la unidad y trascendencia del poder político. Una disputa que el «momento gaditano» exhibió en todas sus dimensiones al experimentar la extraordinaria situación de una monarquía en la que -retomando la imagen consagrada por Ernst Kantorowicz-, el «cuerpo físico» del rey no había muerto sino que había entregado ilegalmente el «cuerpo político» de la Corona ${ }^{95}$.

94 MANENT, 1990: 118.

95 KANTOROWICZ, 2012. 


\section{Bibliografía CITADA}

Berruezo, María Teresa, La participación americana en las Cortes de Cádiz (18101814), Madrid, Centro de Estudios Constitucionales, 1986.

Brancato, Braz, «Os Direitos de Carlota Joaquina à Sucessão Espanhola e a Missão Diplomática de Pedro de Sousa Holstein», en IV Simpósio Internacional Estados Americanos: Relações Continentais e Intercontinentais, Passo Fundo, UPF Editora, 2003: 1-10.

Breña, Roberto, El primer liberalismo español y los procesos de emancipación de América, 1808-1824. Una revisión historiográfica del liberalismo hispánico, México, El Colegio de México, 2006.

Cantos Casenave, Marieta, Durán López, Fernando y Romero Ferrer, Alberto (coords.), La guerra de pluma: Estudios sobre la prensa de Cádiz en el tiempo de las Cortes (1810-1814), Cádiz, Universidad de Cádiz, 2008.

Carta crítica sobre la Disertación histórico-político-legal que trata de la sucesión a la Corona de España, Cádiz, En la Oficina de la viuda de Cosmes, 1811.

Chust, Manuel, La cuestión nacional americana en las Cortes de Cádiz (1810-1814), Madrid, Centro Francisco Tomás y Valiente, 1999.

Clavero, Bartolomé, «La monarquía, el derecho y la justicia», en Enrique Martínez Ruiz y Magdalena de Pazzis Pi (coords.), Instituciones de la España moderna. I. Las jurisdicciones, Madrid, Actas Editorial, 1996.

Clavero, Bartolomé, El orden de los poderes. Historias constituyentes de la trinidad constitucional, Madrid, Editorial Trotta, 2007.

Costa, Fernando Dores, «O Conde de Palmela em Cádis (1810-1812). A crítica das Cortes e a dimensão militar do projeto de candidatura de Carlota de Bourbon a Regência de Espanha», Ler História, 64 (Lisboa, 2013): 87-110.

Dictamen de Don Antonio José Ruiz de Padrón, diputado por Canarias, proponiendo para Regenta del Reyno a la serenísima Señora D. Carlota Joaquina de Borbón, princesa de Brasil, e Infanta de las Españas, Madrid, Imprenta de Dávila, 1814.

Flaquer Montequi, Rafael, «El ejecutivo en la revolución liberal», en Miguel Artola (ed.), Las Cortes de Cádiz, Madrid, Marcial Pons, 2003: 36-65.

Garriga, Carlos, «Gobierno», en Javier Fernández Sebastián y Juan Francisco Fuentes (dirs.), Diccionario político y social del siglo XX español, Madrid, Alianza Editorial, 2008.

Garriga, Carlos y Lorente, Marta, Cádiz 1812. La constitución jurisdiccional, Madrid, CEPC, 2007.

Kantorowicz, Ernest, Los dos cuerpos del Rey. Un estudio de teología política medieval, Madrid, Akal, 2012.

La Parra, Emilio, La libertad de prensa en las Cortes de Cádiz, Alicante, Biblioteca Virtual Miguel de Cervantes, 2005.

La Parra, Emilio, «Aspiraciones a la Corona española tras las abdicaciones de Bayona», en HispanismeS, hors-série, 1 (París, 2017): 151-174. 
Landavazo, Marco Antonio, «La sacralización del Rey. Fernando VII, la insurgencia novohispana y el derecho divino de los Reyes», Revista de Indias, LXI/221 (Madrid, 2001): 67-90.

Lasarte Álvarez, Javier, Las cortes de Cádiz: Soberanía, separación de poderes, Hacienda, 1810-1811, Madrid, Marcial Pons, 2009.

Lorente, Marta y Portillo Valdés, José (dirs.), El momento gaditano. La constitución en el orbe hispánico (1808-1826), Madrid, Cortes Generales, 2012.

Manent, Pierre, Historia del pensamiento liberal, Buenos Aires, Emecé, 1990.

Marques Pereira, Sara, D. Carlota Joaquina e os «Espelhos de Clio», Lisboa, Livros Horizonte, 1999.

Martínez Sospreda, Manuel, «El Rey como poder ejecutivo. La posición del Rey en la Constitución de 1812», Corts. Anuario de derecho parlamentario, 26 (Valencia, 2012): 71-111.

Martiré, Eduardo, «Carlota Joaquina en las Cortes españolas», en Eduardo Martiré (coord.), La América de Carlos IV, vol. 4, Buenos Aires, Instituto de Investigaciones de Historia del Derecho, 2006-2009: 203-250. Cuadernos de Investigaciones y Documentos, $\mathrm{n}^{\mathrm{o}} 1-5$.

Martiré, Eduardo, «Podía legítimamente la reina portuguesa Carlota Joaquina ser regente de España y las Indias», en Anais do Colóquio Ibero Sul-Americano de Historia: entre os Dois Lados do Atlántico, Asunción, Tiempo de Historia, 2009: 113-139.

Moreno Pastor, Luis, «Pascual Bolaños y Novoa: la percepción de un jurista de la crisis de 1808», Cuadernos de Historia del Derecho, vol. extraordinario (Madrid, 2010): 421-447.

Nogueira de Azevedo, Francisca N., Carlota Joaquina na corte do Brasil, Río de Janeiro, Civilizacao Brasileira, 2002.

Pimenta, João Paulo, O Brasil e a América española (1808-1822), tesis doctoral, Faculdade de Filosofia, Letras e Ciências Humanas, Universidade de São Paulo, 2003.

Portillo Valdés, José María, Revolución de nación. Orígenes de la cultura constitucional en España, 1780-1812, Madrid, CEPC, 2000.

Portillo Valdés, José María, Crisis Atlántica. Autonomía e independencia en la crisis de la monarquía hispana, Madrid, Marcial Pons, 2006.

Rieu-Millan, Marie-Laurie, Los diputados americanos en las Cortes de Cádiz: igualdad o independencia, Madrid, CSIC, 1990.

Rubio, Julián María, La infanta Carlota Joaquina y la política de España en América (1808-1812), Madrid, Imprenta de Estanislao Maestre, 1920.

Ternavasio, Marcela, «La princesa negada. Debates y disputas en torno a la Regencia (1808-1810)», en Véronique Hébrard y Geneviève Verdo (eds.), Las independencias hispanoamericanas, Madrid, Casa de Velázquez, 2013: 261-275. Colección de la Casa de Velázquez, 137.

Ternavasio, Marcela, Candidata a la Corona. La infanta Carlota Joaquina en el laberinto de las revoluciones hispanoamericanas, Buenos Aires, Siglo XXI, 2015.

Ternavasio, Marcela, «Diplomacia, linaje y política durante la crisis de las monarquías ibéricas. Disputas en torno a la candidatura de Carlota Joaquina de Borbón entre 1808 y 1810», Historia y Política, 38/2 (Madrid, 2017): 163-193. 
Urquijo Goitia, José Ramón y Álvarez-Coca González, María Jesús, «José Joaquín Colón y la rehabilitación de la monarquía absoluta», Revista de Historia Jerónimo Zurita, 87 (Madrid, 2012): 203-205.

Varela Suanzes-Carpegna, Joaquín, «Rey, corona y monarquía en los orígenes del constitucionalismo español: 1808-1814», Revista de Estudios Políticos, 55 (Madrid, 1987): 123-195.

Recibido: $17 / 03 / 2017$

Aceptado: 23/02/2018 